\title{
Os desafios da construção da Pedagogia Socialista em tempos de ofensiva do capital e crise sanitária
}

\section{Resumo}

Neste texto, problematizamos a construção da Pedagogia Socialista frente à ofensiva do capital, acentuada com a pandemia do Coronavírus, analisando as possibilidades e os limites da educação na perspectiva da classe trabalhadora. Para tanto, discorremos sobre a educação no contexto da luta de classes, em especial na particularidade brasileira dos últimos anos. Em seguida, descrevemos as ações no campo educacional desenvolvidas pelo Movimento dos Trabalhadores Rurais Sem Terra (MST) no contexto da pandemia. Além disso, recuperamos as categorias da pedagogia socialista soviética: Trabalho, Atualidade e Auto-organização, presentes nas formulações teóricas de Pistrak (2009) e Shulgin (2013), ampliando-as e as encharcando da realidade atual, na intenção de compreender a educação na estratégia socialista.

Palavras-chave: Pedagogia Socialista; educação e luta de classes; educação no MST.

\section{Caroline Bahniuk}

Universidade de Brasília - UNB -

Brasília/DF - Brasil

carolbani@gmail.com

\section{Para citar este artigo:}

BAHNIUK, Caroline. Os desafios da construção da Pedagogia Socialista em tempos de ofensiva do capital e crise sanitária. Revista Linhas. Florianópolis, v. 22, n. 49, p. 243-263, maio/ago. 2021. 


\title{
The challenges of the Socialist Pedagogy construction in times of capital assault and sanitary crisis
}

\begin{abstract}
On this text we problematize the Socialist Pedagogy construction facing the capital assault, deepened through the coronavirus pandemic, analyzing both the education possibilities and limits from the working class perspective. Aiming that, we have discussed about education in the class struggle context, specially on the Brazilian particularity in the past years. Next, we have described the actions developed on the educational field by Movimento dos Trabalhadores Rurais Sem Terra (MST) on the pandemic context. In that direction, we have retrieved the categories of the Soviet socialist pedagogy: Labor, Actuality and Selforganization, present on Pistrak (2009) and Shulgin (2013) theory formulations, amplifying as well as soaking them into the actual reality with the purpose of understanding education in the socialist strategy.
\end{abstract}

Keywords: Socialist Pedagogy; education and class struggles; education on MST. 
O objetivo deste texto é refletir sobre a construção da Pedagogia Socialista frente à ofensiva do capital, acentuada com a pandemia do Coronavírus, analisando as possibilidades e os limites da educação na perspectiva da luta da classe trabalhadora.

Compreendemos a Pedagogia Socialista "como um espaço de associação e teorização de práticas educativas protagonizadas pelos trabalhadores ao redor do mundo e conduzidas (na teoria e na prática) desde seus objetivos de classe para a construção de novas relações sociais de caráter socialista" (FREITAS, 2015, p. 7). Esse conceito abarca as experiências educativas históricas e atuais voltadas à superação desse modo de produção e à construção do socialismo, dialoga ou comporta outras formulações correlatas e derivadas dos pressupostos da educação na concepção marxista.

Importante sublinhar que a construção da educação socialista não se realiza em plenitude sob as relações sociais capitalistas; o que identificamos são germes de uma formação humana alargada, alguns contrapontos à pedagogia do capital hegemônica voltada a formar os trabalhadores para aceitação da exploração do trabalho.

Nessa direção, dialogamos com a experiência do Movimento dos Trabalhadores Rurais Sem Terra (MST) ao buscar desenvolver uma educação e uma escola na perspectiva dos trabalhadores, não sem limites e contradições. Essa perspectiva toma como referência a Pedagogia do Movimento, nome dado à concepção educacional do MST, construída a partir das práticas educativas realizadas nas áreas de Reforma Agrária e da sistematização de outras perspectivas educacionais dos trabalhadores. Consideramos a Pedagogia do Movimento como uma das concepções socialistas de educação existentes na atualidade.

Vivemos um momento de extrema complexidade e de agudização da ofensiva do capital sobre o trabalho e seu aprofundamento no contexto de pandemia, o que se revela pela perda dos direitos trabalhistas, pelo aumento do desemprego, da pobreza e da fome, entre tantas outras mazelas sociais, somados às enormes dificuldades de mobilização e organização dos trabalhadores. No âmbito educacional, essa ofensiva desdobra-se num intenso processo de mercantilização da educação, no controle sobre a escola, na ampliação das desigualdades educacionais, entre outros. Frente à destruição 
da educação pública, coloca-se a urgência de construirmos respostas coletivas e radicais de enfrentamento à barbárie em curso.

Sublinhamos que este texto foi escrito num momento em que o Brasil vive a fase mais aguda da pandemia do Coronavírus até então, com uma média de 2.600 mortes diárias, totalizando uma quantidade monstruosa e indignante de mais de 400 mil vidas perdidas ao final de abril de 2021. A indignação amplia-se, uma vez que já temos soluções efetivas: vacinas, combinadas com distanciamento social, e o uso de máscaras para frear a pandemia; mas, todas essas medidas são negadas pelo governo genocida de Jair Bolsonaro.

Isso posto, organizamos o texto em três partes. Na primeira, discutimos as lutas de classes na educação, a partir da particularidade da educação no Brasil dos últimos anos. Na segunda, descrevemos a educação do MST e suas ações no contexto de pandemia. Posteriormente, trazemos algumas categorias da pedagogia socialista: Trabalho, Atualidade e Auto-organização, a partir das formulações teóricas presentes de Pistrak (2009) e Shulgin (2013), para refletir sobre sua construção da educação na estratégia socialista nos dias atuais.

\section{a) As lutas de classes na educação no Brasil e a ofensiva conservadora}

O desafio de compreender a educação, nos dias atuais se realiza num contexto marcado pela crise mundial, pelo aprofundamento da tendência destrutiva do capital e pelo fortalecimento da ideologia da naturalização das relações sociais capitalistas, expressas pela degradação crescente do meio ambiente, pelos elevados índices de desemprego e pobreza, pela diminuição da taxa de uso das mercadorias, dentre elas a força de trabalho, pelo agudo desperdício na produção e no consumo, entre outras contradições que evidenciam o poder destrutivo do atual estágio do capitalismo em crise (MÉSZÁROS, 2005; 2006). Essa crise foi aprofundada na última década e escancarada com a pandemia do Coronavírus, a qual amplia a destrutividade do capital, pelas mortes de milhões de pessoas, pelo aumento do desemprego, da fome e da miséria em escalas exponenciais. 
No Brasil, o ajuste estrutural neoliberal como resposta do capital para continuar se reproduzindo de forma ampliada, vem dilapidando os direitos e a condição de vida dos trabalhadores, o qual está sendo implementado desde a década de 1990. Porém, nos últimos anos, vivemos uma aceleração dramática desse processo, desde o golpe parlamentar que destituiu a presidenta Dilma Rousseff em 2016.

As recentes e diversas modificações no campo jurídico formal materializam esse ajuste, por exemplo, as aprovações: da Emenda Constitucional n 95/2016 - que limita por 20 anos o aumento dos gastos em serviços públicos (saúde, educação, entre outros); da terceirização irrestrita e da Reforma Trabalhista, ambas aprovadas em 2017 e que provocaram uma intensa alteração na Consolidação das Leis do Trabalho (CLT). Como também, já sob o governo Bolsonaro, a aprovação da Reforma da Previdência, garantindo a elevação da idade mínima de aposentadoria e a precarização da assistência social. Todas essas contrarreformas, para citar somente algumas, representam um ataque frontal à classe trabalhadora e seus direitos conquistados historicamente, ao regular e ampliar a flexibilização do trabalho, por meio do emprego parcial, temporário e subcontratado, marcas da intensa precarização do trabalho nos dias atuais.

Ao tomarmos como fio condutor a presença da luta de classes nos diferentes espaços da vida contemporânea, iremos nos dedicar a entender a ofensiva do capital sobre o trabalho, pela particularidade da educação. A educação e a escola, hegemonicamente, contribuem para a internalização e legitimação das relações sociais capitalistas. A educação, para Mészáros (2005), tem por função primeira contribuir na manutenção da reprodução ampliada do capital e, consequentemente, manter a alienação do trabalho e do trabalhador em seus diversos aspectos, realizando um processo de internalização pelos indivíduos de valores e dos parâmetros do capital. Porém, esse processo, não se realiza em absoluto, o que significa afirmar que a reprodução não se efetiva de forma mecânica e direta. Contradições e mediações permeiam a internalização, as quais abrem brechas e permitem confrontar, não sem limites, o processo de internalização do capital e a construção da pedagogia socialista.

Não é de hoje o interesse do capital pela educação, no entanto, a reforma empresarial da educação em curso, desde a década de 1990 no Brasil, revela uma atuação da classe burguesa, qualitativamente distinta. A referida reforma tem instituído, 
sistematicamente, a lógica empresarial na educação pública, em sintonia com a reforma neoliberal do Estado, a qual estimulou uma maior incidência do privado na educação pública.

As principais caraterísticas da reforma empresarial da educação são: a concretização de parcerias público-privadas, por meio da gestão por concessão; a venda de serviços educacionais; o controle do processo pedagógico por avaliação externa; o pagamento de vouchers e/ou bolsas pagas pelo Estado para os estudantes concretizarem seus estudos em escolas privadas; a venda de materiais didáticos; entre outros (FREITAS, 2018). Esse processo acentua a mercantilização da educação, com o direcionamento de verbas públicas para corporações do setor educacional, sobretudo a grandes conglomerados financeiros, presentes em maior volume no mercado do ensino superior e de venda de materiais didáticos (LEHER, 2018).

Para Leher (2018, p. 46), mesmo os governos de coalização petistas não romperam com essa lógica e, apesar de ampliarem o acesso à Educação Básica e Superior, e colocarem em pauta políticas de ações afirmativas importantes, "as ecléticas medidas educacionais do governo do PT (2003-2014) foram harmônicas com a agenda do capital”. Nesse período há um crescimento da interferência da classe empresarial organizada nas políticas educacionais. O exemplo mais emblemático refere-se ao Movimento Todos pela Educação (TPE) ${ }^{1}$. Esse movimento consiste num conglomerado de grupos empresariais que ocultam seu caráter de classe por meio da filantropia e da responsabilidade social, apresentando-se como um movimento "apartidário" e "plural", com a finalidade de cobrar e efetivar melhorias na qualidade da educação pública brasileira, incidindo fortemente nas políticas públicas.

No que diz respeito aos retrocessos das políticas educacionais do último período, temos em curso o “Novo Ensino Médio” aprovado com a Lei n. 13.415/2017 - e a definição da Base Nacional Comum Curricular (BNCC) para Educação Básica; ambas visam restringir a educação ao mercado de trabalho, ou nas palavras dos reformadores "formar os jovens

\footnotetext{
1 O TPE possui organismos correlatos em diversos países da América Latina, que compõem a Rede Latino Americana pela Educação (Reduca). Esses movimentos estão sintonizados com os outros organismos supranacionais que formulam e incidem sobre a educação em nível mundial (Banco Mundial, Unesco, OCDE, Bird, entre outros).
} 
para as competências e habilidades do século XXI”. Em síntese, consiste em uma contrarreforma que

[...] condena gerações ao trabalho simples e nega os fundamentos das ciências que permitem aos jovens entender e dominar como funciona o mundo das coisas e a sociedade humana. Uma violência cínica de interdição do futuro dos filhos da classe trabalhadora por meio da oficialização da dualidade intensificada do Ensino Médio e de uma escola esvaziada, na perspectiva de Antonio Gramsci. (MOTTA; FRIGOTTO, 2017, p. 369)

Para além das reformas citadas, a situação no Brasil se agravou nos últimos anos com a ampliação expressiva de movimentos políticos de extrema direita. As organizações e proposições alinhadas a esses grupos resultaram na ascensão de Jair Bolsonaro (Sem Partido) ao governo federal, alinhado a essa concepção. Desses movimentos se destacam, segundo Lamosa (2018), Estudantes pela liberdade (EPL) e o Movimento Brasil Livre (MBL), entidades brasileiras ligadas a redes internacionais como Atlas Network e Rede Liberdade ${ }^{2}$.

No campo educacional, essa vertente compartilha em grande medida da reforma empresarial da educação, em particular na privatização da educação pública, no controle do processo pedagógico da escola, por meio da formação dos professores e estudantes, sintonizada às habilidades e competências do mercado de trabalho. Ao mesmo tempo, esse grupo reacionário agrega outras pautas e ações, dentre as quais se destacam: o Projeto Escola Sem Partido, homeschooling e a militarização das escolas, os quais compõem a base das políticas educacionais do governo Bolsonaro.

Apesar do Programa Escola Sem Partido ter saído de pauta no congresso nacional, ele conquistou em certa medida seu objetivo de limitar o pensamento crítico e criminalizar os professores, trazendo a ideia falaciosa de "doutrinação política e ideológica". O homeschooling, ou educação doméstica, refere-se à substituição total ou parcial das atividades escolares por atividades em casa. Indo na contramão do direito à

\footnotetext{
${ }^{2}$ Sobre a ascensão desses grupos de extrema direita no Brasil, ver CASIMIRO, Flavio Henrique. A nova direita: aparelhos de ação política e ideológica no Brasil contemporâneo. São Paulo: Expressão popular, 2018.
} 
educação, do acesso a conteúdos universais, e impedindo também os processos de socialização vivenciados na escola.

A militarização das escolas diz respeito ao compartilhamento da gestão da escola pública com militares (policiais, bombeiros e exército). O Ministério da Educação instituiu em 2019 uma subsecretaria de fomento às escolas cívico-militares, para estabelecer parcerias com estados e municípios que desejem militarizar parte de suas escolas. Para Freitas (2018) e Lamosa (2018), há nessas escolas uma exacerbação da disciplina rígida e autoritária, em particular no que se refere ao controle da conduta moral de estudantes; ao mesmo tempo, ferem a autonomia e a gestão democrática das escolas públicas, principalmente nas escolas de regiões mais periféricas.

Para Lamosa (2018), nos últimos anos, no campo educacional, disputam no interior da classe burguesa duas frentes: a social liberal e a ultraconservadora. A frente social liberal tem como uma de suas grandes expressões o movimento Todos pela Educação, conforme abordamos anteriormente. A frente ultraconservadora dissemina um projeto de criminalização dos professores e da escola. O autor destaca as divergências entre as duas frentes, porém busca indicar as convergências que não se encontram tão aparentes, mas que, na sua análise, se verificam pela adesão aos projetos de ambas as frentes, e também pela presença de intelectuais em ambas as frentes.

Os cortes e os contingenciamentos de recursos na educação também são uma tônica do atual governo federal, que parece ter escolhido como um dos seus alvos a educação pública, destruindo-a pelo sucateamento, como também pela tentativa de controle e alinhamento das instituições ao governo, vide por exemplo, a indicação de reitores interventores em diversas instituições federais de ensino superior.

Essa ofensiva do capital sobre o trabalho não tem sido realizada sem lutas e enfrentamentos da classe trabalhadora. Em particular, na última década, vivenciamos as lutas pela defesa da universidade pública, gratuita e de qualidade; as lutas do Magistério da Educação Básica por condições de trabalho; as lutas dos estudantes com a ocupação das escolas contra a Reforma do Ensino Médio; a luta do Movimento dos Trabalhadores Sem Terra pela educação e pela garantia de gerir coletivamente as escolas públicas em acampamentos e assentamentos da Reforma Agrária, a partir de seus princípios filosóficos e pedagógicos, entre muitas outras. 
No contexto da pandemia, a investida do capital e mercantilização da educação ampliam-se com a imposição do ensino remoto ao conjunto das escolas públicas brasileiras. Iremos debater a particularidade dos nossos dias e o lugar da educação na construção da estratégia socialista a partir da educação do MST e das categorias centrais presentes na experiência socialista soviética, o que faremos nos tópicos que seguem.

\section{b) A educação do MST na pandemia}

Ao longo de sua existência de quase quatro décadas, a questão educacional sempre se fez presente no MST. Inicialmente, como necessidade de dar respostas à presença de crianças nos acampamentos e, com o desenrolar das experiências educacionais, construindo uma concepção educacional, denominada de Pedagogia do Movimento. Segundo Caldart (2015), essa concepção possui como fontes constitutivas: a Pedagogia Socialista - em especial as experiências da Revolução Russa e Cubana; juntamente com a Pedagogia do Oprimido de Paulo Freire e o próprio Movimento em seu jeito de realizar a luta pela terra.

O MST, por meio do seu Setor de Educação, constituído local e nacionalmente, atua realizando diversas ações em frentes distintas: nas escolas públicas das áreas de Reforma Agrária; com as crianças e jovens, na intenção de integrá-los na organicidade e identidade do Movimento; na formação (inicial e continuada) dos educadores, estimulando os militantes do Movimento a tornarem-se educadores nos espaços educativos do Movimento (KOLLING; VARGAS; CALDART, 2012).

Em relação às escolas, o MST luta para que os Sem Terra tenham acesso a todos os níveis de escolarização, e pela construção de escolas públicas dentro das áreas de Reforma Agrária. Segundo Mariano (2019), são aproximadamente duas mil escolas públicas (estaduais e municipais) nos assentamentos e acampamentos do MST, das quais 120 ofertam até o Ensino Médio e 200 possuem o Ensino Fundamental completo; as demais ofertam apenas os Anos Iniciais do Ensino Fundamental. Essas escolas envolvem em números aproximados 160 mil crianças, adolescentes, jovens e adultos Sem Terra. Porém, não são todas as escolas dentro dos assentamentos/acampamentos vinculadas à 
Pedagogia do MST, o que depende de um conjunto de fatores, em particular o vínculo da escola e da comunidade com as lutas e a organicidade do Movimento.

Nas últimas décadas, os trabalhadores do campo vêm enfrentando um processo sistemático de fechamento das escolas em suas comunidades. Desde 2011, o MST realiza a campanha "Fechar escola é crime"; como resultado dessas reivindicações, garantiu a aprovação de uma lei nacional instituindo a consulta às comunidades para o fechamento das escolas. Apesar disso, as escolas do campo seguem sendo fechadas em grande quantidade, visto que entre 1997 e 2018, segundo dados do INEP, foram fechadas 80 mil escolas no campo. Essa situação limita o direito à educação, ao colocar os estudantes a percorrerem longos trajetos para chegar à escola, muitas vezes, com transporte escolar precário (ALENTEJANO; CORDEIRO, 2019), ou ainda numa escola distante da realidade em que vivem, sofrendo por vezes discriminação. O movimento da Educação do Campo, desde a sua constituição, nas últimas décadas denuncia as extensas desigualdades educacionais existentes no campo.

Com a emergência da pandemia, o MST prossegue efetuando um conjunto de ações de luta, solidariedade, de formação e educação dos militantes. Por exemplo, a distribuição sistemática de alimentos nos diversos estados em que se encontra organizado. Alimentos esses produzidos nos acampamentos e assentamentos ${ }^{3}$. Essa distribuição se realiza, principalmente, junto aos trabalhadores moradores das periferias urbanas, os quais têm vivenciado a intensa precarização das suas condições de vida na pandemia.

Além disso, o Movimento tem construído campanhas de informação de enfrentamento à COVID, realizado diversos debates públicos sobre as questões relativas ao projeto de Reforma Agrária Popular e cursos de formação política, de forma remota. Ademais, continua participando das lutas junto a outros movimentos sociais, sindicais e frentes populares, articulando-se a partir das pautas prioritárias: "Vacina já, gratuita e para todos!”; “Auxílio emergencial de 600 reais e Fora Bolsonaro”, articuladas à estratégia do "Movimento em curso de construir e lutar para a Reforma Agrária Popular!".

3 Como, por exemplo, o MST no Paraná que, desde abril de 2020, distribuiu mais de 533 toneladas de alimentos somente nesse estado. E mais de 52 mil refeições também foram partilhadas em Curitiba, pela ação da Marmitas da Terra, coordenada pelo Movimento (MST- PR, C2021). 
Essa estratégia política foi atualizada no VI Congresso Nacional realizado em 2014, na intenção de calibrar forças para o enfrentamento ao capital e ao agronegócio, e ao mesmo tempo construir novas bases produtivas, sociais e culturais nos assentamentos voltadas à transformação social. Nesse momento ganha maior centralidade a questão da agroecologia, como a agricultura voltada à produção de alimentos saudáveis para a população brasileira, numa circunstância de bloqueio da Reforma Agrária clássica e do aprofundamento da mercantilização da natureza e da espoliação dos bens naturais por empresas transnacionais, o que produz uma nova aliança das frações das classes dominantes, com a fusão dos latifundiários com o capital financeiro/ e ou rentista, com o capital monopolista. Essa nova configuração tem provocado um processo acelerado de concentração de terras nas mãos de médios e grandes proprietários que controlam o agronegócio de $85 \%$ das terras no Brasil, com a produção majoritária da monocultura de grãos voltada à exportação, com o uso intensivo de agrotóxicos e redução de empregos no campo (MARTINS; NUNES; GASPARIN, 2021).

Particularmente, o Setor de Educação soma-se às atividades do MST como um todo, e realiza ações junto às crianças, jovens, adultos e educadores do Movimento. Em relação à educação na pandemia, em agosto de 2020, o Movimento lança a campanha “Volta às aulas na pandemia é crime: em defesa da vida e da educação pública!", para denunciar os riscos da retomada das aulas em momento tão delicado, e ao mesmo tempo, as dificuldades e limites, ainda mais intensos, do ensino remoto nas áreas rurais ${ }^{4}$.

Sistematicamente, esse setor tem indicado aos militantes do MST um conjunto de filmes, vídeos, atividades, contos que podem ser assistidos, executados e lidos envolvendo as crianças e as famílias. Bem como, estimulados à participação em outras campanhas encampadas pelo MST, de Literatura e Desenho e o Plantio de árvores e produção de alimentos saudáveis 5 .

\footnotetext{
${ }^{4}$ O Censo da Educação Básica de 2020 (BRASIL, 2020), aponta que 52,2\% das escolas municipais de Ensino Fundamental possuem internet banda larga (INEP/MEC). O acesso à internet nas escolas do campo, e as escolas dos assentamentos e acampamentos é bastante precário, pela nossa experiência e contato com essas escolas. Os relatos dos educadores das áreas de Reforma Agrária reforçam a realidade de não acesso ao ensino remoto por muitos estudantes nas áreas de Reforma Agrária.

5 Essa última, segundo informações coletadas da página do MST, está em curso desde o início de 2020, antes da pandemia, e pretende envolver o conjunto dos Sem Terra e a sociedade em geral para plantar 100 milhões de árvores em dez anos, construindo agro-florestas e quintais produtivos. Esse plano tem por objetivo denunciar a destruição desenfreada realizada pelo agronegócio, colocar em pauta a necessidade
} 
Outra constante na Educação do MST refere-se à formação continuada dos educadores e sua organização coletiva. Em vista disso, no contexto de pandemia, o MST realizou, de forma virtual, duas plenárias dos educadores da Reforma Agrária (outubro de 2020, março de 2021), nas quais se discutiram questões da conjuntura geral e educacional. Realizou-se troca de experiências entre educadores do MST, fortalecendo as linhas políticas a serem empreendidas por eles, e também revigorando, dentro do possível nesse contexto e formato, a mística e a coletividade entre os educadores.

Outra proposta nesse sentido tem sido a construção de grupos de estudos envolvendo os educadores ${ }^{6}$, em particular, destacamos o curso Reforma Agrária Popular e Educação, no segundo semestre de 2020 e sua segunda edição, prevista para o segundo semestre de 2021, com vistas a desenvolver subsídios teórico-práticos da Pedagogia do MST e questões da educação na atualidade. E, também, o curso realidade brasileira “Paulo Freire, um educador do povo!", que está sendo realizado de abril a agosto do corrente ano, e tem por objetivo conhecer os conceitos e as ideias centrais de Paulo Freire, compondo a Jornada Nacional Viva Paulo Freire!7, comemorativa ao centésimo ano de nascimento desse educador brasileiro e uma das fontes inspiradoras da Pedagogia do MST.

Esse conjunto de ações articuladas desenvolvidas pelo MST no campo da educação e em relação ao todo do Movimento, mostra sua força, que busca construir outras relações sociais, não sem limites, mas com a intenção de confrontar e desnaturalizar o projeto particularista do capital e sua educação correspondente.

\footnotetext{
de um cuidado coletivo com os bens da natureza, e também a produção e consumo de alimentos saudáveis, produzidos pelos camponeses, com a massificação da agroecologia.

${ }^{6}$ Formação em Tempos de Corona: https://sites.google.com/view/mstformcaocvd19/in\%C3\%ADcio

7 A jornada é composta por diversas atividades, dentre as quais a construção de um site, https://mst.org.br/jornada-nacional-viva-paulo-freire/, no qual se encontra um dossiê especial com diversas informações e conteúdo sobre a vida e obra de Paulo Freire.
} 


\section{c) A construção da Pedagogia Socialista em tempos de mercantilização da educação e crise sanitária}

Como dissemos na parte introdutória deste texto, a pedagogia socialista diz respeito às experiências educativas realizadas pelos trabalhadores de caráter socialista, de maneira que ela "se desenvolve no seio das contradições e da luta de classes historicamente dadas. Portanto, no plano da ontologia materialista não se trata de um projeto do dever ser, mas da ação teórica e prática na transformação das relações sociais capitalistas" (FRIGOTTO, 2017, p. 16). Dessa forma, a Pedagogia Socialista é um projeto futuro, mas que se constrói desde já, recuperando em certo sentido experiências passadas, não para copiá-las, mas sim para refletir sobre elas e construir algo novo, condizente com o tempo histórico atual.

A Revolução Russa foi uma das primeiras experiências socialistas construídas pelos trabalhadores; nela, os pioneiros da educação sistematizaram uma concepção de educação e escola articulada à revolução referenciadas nas categorias: Trabalho, Atualidade e Auto-organização, presentes nas formulações teóricas de Pistrak (2009) e Shulgin $(2013)^{8}$. Esses autores ajudaram a construir uma concepção educacional, na intenção de formar lutadores e construtores da nova sociedade em curso no período.

Ao recuperarmos alguns aspectos dessa experiência educacional, não temos a intenção de tomá-la como modelo a ser seguido, pois temos clareza da distância entre a Rússia revolucionária do início do século XX e nossos dias, bem como das limitações e contradições presentes naquele momento, na tentativa de desenvolver uma educação a partir dos fundamentos marxistas. Nosso processo de análise elege as categorias centrais dessa experiência como fio condutor da discussão proposta, no entanto, para compreender a pedagogia socialista em nosso tempo, elas são encharcadas e lapidadas pela realidade atual.

\footnotetext{
${ }^{8}$ Em nossos estudos, desde nossa tese de doutorado (BAHNIUK, 2015), recuperamos algumas categorias a partir das primeiras experiências educacionais socialistas: Comuna de Paris e Revolução Russa. Além das categorias citadas acima, outras compuseram esse estudo: Radicalização do público, Formação Omnilateral, Conhecimento.
} 
O trabalho é o fundamento central da pedagogia socialista. A proposta de escola construída posteriormente à revolução chamava-se de Escola Única do Trabalho ${ }^{9}$, em que o trabalho era compreendido como articulador do processo educativo, distinguindo-se e não restrito ao ensino profissionalizante.

A ligação entre trabalho e educação não é uma criação dos pioneiros da educação soviética; ela encontra-se em Marx e advém muito antes dele na proposta educacional dos socialistas utópicos, burgueses e outros. Porém Pistrak (2009) e Shulgin (2013) vão se dedicar a desenvolver a relação entre trabalho e escola como um aspecto formativo central da formação socialista. Para eles, o trabalho na escola não deve se restringir à ilustração dos conhecimentos, nem a um saber fazer voltado a aprendizagens de técnicas de trabalho, ou ainda desenvolver nos estudantes o amor pelo trabalho. Para eles, o trabalho como organizador da escola é tido como parte do trabalho social, e seu desenvolvimento requer a unidade entre teoria e prática, na intenção de garantir o domínio intelectual dos processos de produção.

A complexidade do trabalho desenvolvido na escola soviética era determinada considerando a idade dos estudantes, ao mesmo tempo em que dizia respeito a um trabalho real e de importância para a comunidade e para escola, e apresentava um valor pedagógico, o que Shulgin chamou de Trabalho Socialmente Necessário (TSN). Não era, dessa forma, qualquer trabalho interessante à escola, mas o trabalho com essas características.

O trabalho, a partir do referencial marxista, possui uma dupla dimensão de ser, ao mesmo tempo ontológico e histórico. Sua dimensão ontológica refere-se à relação entre ser humano e natureza voltada a atender as necessidades humanas. O trabalho nos constitui como seres humanos e nos diferencia dos animais. Porém é histórico, alterandose ao longo do tempo, determinado pelo modo de produção vigente. Sob o capitalismo, a dimensão histórica do trabalho refere-se à alienação, derivada da apropriação privada da riqueza pela classe dominante. Nessas relações, sua dimensão humanizadora encontra-se

\footnotetext{
9 Sobre escola única do trabalho, ver dois documentos do período, a "Deliberação do comitê executivo central de toda a Rússia", de outubro de 1918, sistematizado pelo Partido Comunista. E a "Declaração sobre os princípios fundamentais da escola única do trabalho", construída a partir do primeiro e publicada no mesmo ano. Ambos os documentos estão traduzidos como anexos da obra: KRUPSKAYA, N. K. A construção da pedagogia socialista. São Paulo: Expressão Popular, 2017.
} 
subsumida pela exploração do trabalho, gerando desumanização (MANACORDA, 2010; MARX, 2006).

No que diz respeito à educação, o trabalho é um dos pilares da proposta educativa do MST, uma constante desde as primeiras formulações sobre a escola. No entanto, vários estudos sobre educação no MST também destacam as dificuldades de realizar essa dimensão no interior do MST. Por vezes, na escola, o trabalho se apresenta como atividades pontuais, sem relação com o todo da escola e com o trabalho social. A articulação potencial se apresenta na relação entre as práticas educativas ao trabalho de novo tipo nos espaços de Reforma Agrária, por exemplo, o trabalho cooperado e a agroecologia $^{10}$ - diretrizes do MST para produção nos acampamentos/assentamentos, incipientes, no entanto, presentes em alguns acampamentos e assentamentos (BAHNIUK, 2015).

Olhando as ações do MST durante a pandemia, essas possíveis articulações podem ter aparecido, a depender de como elas foram desenvolvidas. Nesse sentido, alguns questionamentos surgiram: Qual o sentido educativo de envolver as crianças, adolescentes e jovens da Educação Básica em ações de solidariedade como, por exemplo, a distribuição de alimentos e a plantação de árvores? Como as escolas participaram e participam dessas intervenções? Qual a relação entre elas e o conhecimento científico/ escolar? Como elas influenciam na auto-organização dos estudantes?

A atualidade é a segunda categoria trazida da experiência soviética. Ela remete à centralidade da luta de classes em determinado período histórico. Para os pioneiros da educação soviética, dizia respeito à contribuição para que os estudantes compreendessem o cerne e o seu lugar na luta pela construção do socialismo na Rússia frente ao imperialismo capitalista (PISTRAK, 2009). Essa dimensão está visceralmente articulada com as lutas sociais.

A atualidade do nosso tempo histórico refere-se ao reconhecimento da essência da luta de classes, e do nosso papel enquanto classe trabalhadora frente à ofensiva do capital sobre o trabalho, ampliada na crise sanitária em curso. Falar em atualidade não

\footnotetext{
10 Sobre a relação entre Educação do MST e Agroecologia, ver: ESCOLAS DO CAMPO E AGROECOLOGIA: uma agenda de trabalho com a vida e pela vida. Porto Alegre, 2016. Disponível em: https://www5.unioeste.br/portalunioeste/arq/files/GEFHEMP/01_Escolas_do_C ampo_e_Agroecologia.pdf. Acesso em: 05 abr. 2021.
} 
significa negligenciar os processos e determinações históricas, porém mostrar a relação entre história e realidade atual, como os processos históricos compõem a atualidade. $\mathrm{Na}$ particularidade brasileira, essa dimensão se impõe de maneira mais dramática, frente ao avanço da extrema direita com o governo de Bolsonaro, à negação da gravidade da pandemia e à irresponsabilidade de administração de medidas sanitárias para controlar o Coronavírus.

As palavras de ordem ditas pelo conjunto de organizações da classe trabalhadora, “Vacina, pão, saúde e educação", juntamente com o “Fora Bolsonaro”, estão na ordem do dia das mobilizações sociais. Apesar de enfraquecido, com maiores índices de rejeição, o governo Bolsonaro segue realizando seu projeto de destruição dos serviços públicos e de morte, não operando políticas de contenção do vírus, como também piorando a condição de vida de milhares de brasileiros.

Soma-se a essas pautas a necessidade de barrar a Reforma Administrativa, a qual se apresenta como mais um ataque frontal ao serviço público; frear as privatizações das empresas estatais e garantir direitos aos trabalhadores. No campo educacional, é mister derrotar o projeto de lei $n^{\circ} 5595 / 2020$ que pretende tornar a educação um serviço essencial, para realizar a abertura das escolas e universidades no pior momento da pandemia, como também esse projeto incide sobre o direito de greve dos trabalhadores da educação. Hoje vivemos um grande embate sobre a reabertura ou não das escolas. Muitas instituições privadas já voltaram suas atividades presenciais, assim como diversas redes públicas. Porém, os impactos serão nefastos com a aprovação do Projeto de Lei $(\mathrm{PL})$, tanto no agravamento da pandemia como nos direitos do trabalho dos professores. Além disso, vivenciamos os extensos cortes orçamentários no campo educacional, juntamente com as políticas educacionais ultraconservadoras que mostram ser a educação um dos alvos prioritários de intervenção e controle desse governo.

Cabe aos trabalhadores denunciar e lutar contra a mercantilização da educação, e tomar para si o controle da educação pública, afastando a influência de conglomerados educacionais das políticas educacionais. A desmercantilização da educação é um fator importante para refletir e impulsionar a educação numa perspectiva socialista nos dias atuais. Essa questão refere-se à democratização do ensino, na intenção de garantir o acesso e permanência da classe trabalhadora em todos os níveis, não se acomodando 
com a insuficiência de uma educação empobrecida de sentido, e nem se restringindo ao campo do direito.

Em tempos de ensino remoto e/ou híbrido, a venda de serviços e pacotes tecnológicos para as redes de ensino público aumentaram, com o uso plataformas tecnológicas para as atividades remotas, as quais têm intensificado a privatização, a burocratização e a precarização do ensino. O que coloca como urgência a luta contra a armadilha do ensino remoto e suas perversas consequências, dentre elas o aumento das desigualdades educacionais desde o acesso e a permanência da camada mais empobrecida das classes populares à educação pública sobre essas condições. Ao mesmo tempo, lutar para construir condições para o retorno presencial das escolas públicas, requer a vacinação dos profissionais da educação, juntamente com o controle da pandemia e da melhoria da estrutura das escolas (ventilação, distanciamento, diminuição de alunos por turma, contratação de professores, entre outros).

Essas lutas no campo educacional são urgentes e muitas, no entanto, a educação não resolverá sozinha seus problemas, uma vez que, como vimos, ela faz parte de uma estratégia de dominação do capital sobre os trabalhadores. Assim sendo, a resolução de fato dessas questões, pressupõe romper com o modo de produção capitalista e sua educação hegemônica. Nesse sentido, é fundamental articulação das lutas educacionais e a outras lutas mais imediatas e de sobrevivência da classe trabalhadora, com a estratégia socialista.

Leher $(2010 ; 2018)$ destaca o teor pedagógico presente nas lutas pela educação pública, ao ampliar o alcance dessas lutas e os sujeitos envolvidos, podendo vir a acumular forças na organização da classe trabalhadora. Todas essas lutas não podem perder de vista a necessidade de organização da classe na direção da superação do modo de produção capitalista, questão essa que debateremos no item a seguir.

Pistrak (2009) e Shulgin (2013) se dedicaram a refletir sobre a auto-organização dos estudantes na escola, na direção de formar os estudantes, desde a infância, para construção da nova sociedade socialista, com o desenvolvimento da capacidade de trabalhar em grupo, de coordenar e ser coordenado, de se responsabilizar por sua vida, pelo coletivo, pela escola. Propunham também que a escola se relaciona com outras 
organizações de crianças e jovens ligadas com a organização da classe trabalhadora como um todo.

A auto-organização será destacada extrapolando a escola e os estudantes, refletindo sobre a sua necessidade na classe trabalhadora, como uma tarefa educativa. Como discutimos, a classe trabalhadora não é um todo homogêneo, vive processos de fragmentação e perda de sua dimensão aguerrida, pela ofensiva do capital, num contexto de reestruturação produtiva. Na particularidade brasileira das últimas décadas, pode ser reconhecida pela perda da combatividade de diversos instrumentos da classe trabalhadora: partidos, sindicatos e movimentos sociais, frente a governos de conciliação de classes, como foram os governos petistas, e mais recentemente pela criminalização das lutas pelo governo de extrema-direita. Agrava-se a isso a necessidade do distanciamento social, limitante do encontro presencial das pessoas na pandemia.

A organização da classe trabalhadora é um processo teórico-prático, que envolve a construção de ações coletivas, organização e estudo. Nesse aspecto, percebemos no MST um processo contínuo de realização de ações diretas, mas também de estudo voltado a compreender a realidade atual, e o reconhecimento por esse Movimento de que os processos organizativos precisam estar articulados com a formação política e educativa da classe trabalhadora. Essa dimensão formativa engloba, dentre outros aspectos, a compreensão: da realidade e suas contradições para além da aparência, das experiências de emancipação históricas dos trabalhadores e as possibilidades de construí-las no presente. Para tanto, o conhecimento científico e escolar são parte desse processo; destituir os trabalhadores desse conhecimento significa destituí-los da possibilidade de conhecer e intervir na realidade de forma autônoma.

No que diz respeito aos professores, essa formação contínua e crítica também é fundamental. Ela pode garantir maior autonomia para compreender e criar estratégias de resistência às determinações estatais que chegam às escolas. Em geral, a formação continuada dos professores do MST envolve estudos mais gerais da conjuntura e da formação social brasileira; dos fundamentos da pedagogia socialista e da própria pedagogia do MST, entre outros.

Apesar de termos poucas mobilizações massivas pela conjuntura e pela pandemia, identificamos várias intervenções realizadas por coletivos organizados no interior da 
classe trabalhadora, de agitação contra as políticas atuais em defesa dos trabalhadores, como também diversas ações de solidariedade de classe, junto aos trabalhadores destituídos de condições mínimas de sobrevivência.

Porém, um destaque parece fundamental na particularidade da organização da classe no Brasil atual: o movimento revolucionário da classe trabalhadora não se restringe ao processo eleitoral. No caso brasileiro, as eleições presidenciais de 2022 são muito limitadas para a construção da estratégia socialista. A organização e a formação da classe trabalhadora na estratégia socialista precisam direcionar as demandas imediatas ao seu objetivo maior, não descuidar e construir um duplo poder dos trabalhadores organizados, desde seus locais de trabalho, moradia e estudo na direção da superação do capital.

Como apontamos anteriormente, o desafio colocado aos trabalhadores incide na articulação das lutas educacionais entre si e do projeto de transformação social, num processo de reconstrução e fortalecimento das organizações dos trabalhadores no Brasil, com vistas a superar a pedagogia do capital e o próprio capitalismo, condição posta para superar a barbárie e a destruição sem medida do ser humano e da natureza em nossos dias. Lutar e construir, duas palavras presentes na estratégia do MST de hoje que podem nos dar algumas pistas. Porém o caminho será conquistado e construído pelo conjunto dos trabalhadores e suas organizações em unidade, tendo como horizonte a estratégia socialista. 


\section{Referências}

ALENTEJANO, Paulo; CORDEIRO, Tássia. 80 mil escolas no campo brasileiro foram fechadas em 21 anos. Brasil de Fato, São Paulo, 2019. Disponível em:

https://www.brasildefato.com.br/2019/11/29/artigo-or-80-mil-escolas-no-campo-brasileiroforam-fechadas-em-21-anos. Acesso em: 8 abr. 2021.

BAHNIUK, Caroline. Experiências escolares e estratégia política: da Pedagogia Socialista à atualidade do MST. 365f. 2015. Tese (Doutorado em Educação) - Programa de PósGraduação em Educação, Universidade Federal de santa Catarina, Florianópolis, 2015.

BRASIL. Instituto Nacional de Estudos e Pesquisas Educacionais Anísio Teixeira (Inep). Censo da Educação Básica 2020: resumo técnico. Brasília, DF: INEP, 2021.

CALDART, Roseli. Pedagogia do movimento e complexos de estudos. In: SAPELLI, Marlene; FREITAS, Luiz Carlos; CALDART, Roseli (orgs.). Caminhos para a transformação da escola 3: organização do trabalho pedagógico das escolas do campo. São Paulo: Expressão Popular, 2015. p. 19 -66.

CASIMIRO, Flavio Henrique. A nova direita: aparelhos de ação política e ideológica no Brasil contemporâneo. São Paulo: Expressão popular, 2018.

FREITAS, Luiz Carlos. Apresentação. In: PISTRAK, M. Ensaios sobre a escola politécnica. São Paulo: Expressão Popular, 2015. p. 7-11.

FREITAS, Luiz Carlos. A reforma empresarial da educação: nova direita, velhas ideias. São Paulo: Expressão Popular, 2018.

FRIGOTTO, Gaudêncio. O legado de Marx para a construção do projeto da Pedagogia Socialista. CALDART, R. S.; VILLAS BÔAS, Rafael (orgs.). Pedagogia socialista: legado da revolução de 1917 e desafios atuais. São Paulo: Expressão Popular, 2017, p. 207-232. p. 207232.

KOLLING, Edgar; VARGAS, Cristina; CALDART, Roseli. MST e a educação. In: CALDART, Roseli Salete et al. (org.). Dicionário da Educação do Campo. Rio de Janeiro: Escola Politécnica de Saúde Joaquim Venâncio; São Paulo: Expressão Popular, 2012. p. 502-509.

LAMOSA, Rodrigo. Todos pela educação? A ofensiva empresarial no interior do Estado ampliado. In: SIMPÓSIO ESTADO E PODER, 10., 2018, Niterói. Anais [...]. Niterói: UFF, 2018. Tema: Estado Ampliado. p. 91-108.

LEHER, Roberto. 25 anos de Educação pública: notas para um balanço do período. In: GUIMARÃES, Catia (org.). Trabalho, educação e saúde: 25 anos de formação politécnica no SUS. Rio de Janeiro: EPSJV, 2010. p. 29-72.

LEHER, Roberto. Universidade e heteronomia cultural no capitalismo dependente: um estudo a partir de Florestan Fernandes. Rio de Janeiro: Consequência, 2018. 
MANACORDA, Mario. Marx e a pedagogia moderna. 2. ed. Campinas: Editora Alínea, 2010.

MARIANO, Alessandro Santos. Pedagogia da Resistência e o projeto educativo das escolas do MST. In: CÁSSIO, Fernando (org.). Educação contra a barbárie: por escolas democráticas e pela liberdade de ensinar. São Paulo: Boitempo, 2019. p. 175-180.

MARTINS, Adalberto; NUNES, Débora, GASPARIN, Geraldo. Reforma Agrária Popular. In: STAUFFER, Anakeila et al. (org.). Dicionário de agroecologia e educação. Rio de Janeiro: Escola Politécnica de Saúde Joaquim Venâncio; São Paulo: Expressão Popular, 2021. No prelo.

MARX, Karl. O capital: crítica da economia política. 25. ed. Rio de Janeiro: Brasiliense, 2006. v. 2.

MÉSZÁROS, István. A educação para além do capital. São Paulo: Boitempo, 2005.

MÉSZÁROS, István. Para além do capital. São Paulo: Boitempo, 2006.

MOTTA, Vania; FRIGOTTO, Gaudêncio. Por que a urgência da reforma do ensino médio? medida provisória n. 746/2016 (lei n. 13.415/2017). Revista Educação e Sociedade, Campinas, v. 38, n. 139, p. 355-372, abr./jun. 2017.

MST- PR. Famílias do MST preparam doações de alimentos em 14 cidades do Paraná. [S.I.], c2021. Disponível em: https://mst.org.br/2021/04/15/familias-do-mst-preparam-doacoes-dealimentos-em-14-cidades-do-parana/. Acesso em: 18 abr. 2021.

PISTRAK, Moisey. M. A escola comuna. São Paulo: Expressão Popular, 2009.

SHULGIN, Viktor. N. Rumo ao politecnismo, 1. ed. São Paulo: Expressão Popular, 2013. 